\title{
A OCUPAÇÃO DO COMPLEXO DO ALEMÃO NA REPORTAGEM EM QUADRINHOS DO EXTRA
}

Raiane Nogueira Gama*

Resumo: Em meio a uma profusão de adaptações de obras para diferentes mídias e a uma pujante discussão sobre os rumos da imprensa, o jornalismo em quadrinhos ganha relevo como uma alternativa para atender às atuais demandas do mercado. Este artigo debruça-se sobre essa incipiente semiótica-objeto com a análise da reportagem em quadrinhos O fim, do jornal Extra, sobre a ocupação do Complexo do Alemão pelas forças de segurança do Estado do Rio de Janeiro. Ancoramo-nos na semiótica discursiva para examinar como a linguagem jornalística é reconstruída na linguagem quadrinística nesse caso e a tensão entre os efeitos de realidade e ficcionalidade resultante desse movimento.

Palavras-chave: Jornalismo em quadrinhos. Semiótica discursiva. Linguagens híbridas.

\section{INTRODUÇÃo}

A multiplicidade de mídias existentes hoje fomenta o surgimento de uma grande variedade de adaptações de obras para diferentes modos de circulação. Best-sellers dão origem a filmes ou séries, jogos eletrônicos viram livros, histórias em quadrinhos (HQs) migram do papel para as telas do cinema, entre outras produções. A essa tendência ao trânsito entre linguagens alia-se um momento de profundas transformações no jornalismo, que investe crescentemente em uma diversificação de públicos e produtos. $O$ desenvolvimento das tecnologias de informação e comunicação eletrônicas tem modificado determinantemente os modos de produção, distribuição e consumo de notícias nos últimos anos, apontando novos horizontes para a atividade. Diante desse cenário, o jornalismo em quadrinhos (JQ) - estabele- 
cido a partir do início da década de 1990, com a atuação do jornalista e quadrinista maltês-americano Joe Sacco - desponta como uma aposta para atender de forma eficiente às atuais demandas do mercado. Mais do que isso, coloca-se como uma desafiadora semiótica-objeto, que instaura uma nova práxis, uma nova prática de produção discursiva engendrada pelo uso e, por isso, requer a definição de parâmetros gerais de análise capazes de abranger suas diversas dimensões.

Com esse intuito, este artigo propõe uma sistematização do jornalismo em quadrinhos à luz dos parâmetros definidos no âmbito do projeto temático sobre traduções intersemióticas, passagem de um sistema semiótico a outro, em andamento no Laboratório de Semiótica (LabS/UFF), integrado ao Grupo de Pesquisa em Semiótica e Discurso (SeDi/CNPq). O Grupo visa dar formulações pautadas na semiótica discursiva a questões caras aos estudos de tradução e de adaptação - como o papel do tradutor e a questão da fidelidade -, buscando compreender o quanto as coerções das linguagens envolvidas em uma adaptação podem influenciar no seu resultado. Propomos, ainda, uma reflexão sobre o JQ como uma abertura de caminho para a construção de uma linguagem híbri$\mathrm{da}$, "em que os elementos característicos de cada uma [das linguagens em jogo] se encontrem equalizados ou numa politica de dominância branda" (MANCINI, 2018, p. 26). Assim, a partir da análise da reportagem em quadrinhos O fim, do jornal carioca Extra, sobre a ocupação do conjunto de favelas do Complexo do Alemão pelas forças de segurança do estado do Rio de Janeiro, examinamos como as estratégias de textualização tipicamente adotadas na linguagem jornalística são reconstruídas na linguagem quadrinística e que efeitos de sentido resultam desse movimento.

Mais especificamente, investigamos de que maneira se estabelece na reportagem em questão o jogo de forças entre os universos factual e ficcional. De um lado, a objetividade - traduzida na concepção reducionista de que "os fatos falam por si" - se coloca como uma questão fundamental ao jornalismo, tema central das teorizações do campo e noção sacralizada como um dos princípios éticos da profissão (cf. MORETZSOHN, 2001). De outro, temos os quadrinhos tradicionalmente associados "a postulados de escapismo e fantasia, já que suas primeiras histórias e séries vinculavam-se principalmente a temas como o culto ao herói, a ficção científica, a aventura e o humor" (NECO, 2010, p. 21). Perguntamo-nos, então, que efeitos de sentido resultam da passagem de uma linguagem canonicamente caracterizada pela veiculação de fatos e por um ideal de objetividade para uma fortemente marcada pela ficção e por um grau maior de subjetividade. Verificamos a hipótese de que o JQ procura construir um simulacro de aproximação ao jornalismo tradicional, com um esforço para a preservação das características de seu modo prototípico de enunciar. Tal manutenção se faz necessária para legitimar e garantir credibilidade a esse formato de relato jornalístico.

\section{DA TRADUÇÃO INTERSEMIÓTICA AO HIBRIDISMO ENTRE LINGUAGENS}

No âmbito do projeto temático no qual este trabalho se insere, partimos do conceito de tradução intersemiótica desenvolvido inicialmente por Jakobson (1969) e aprofundado posteriormente na semiótica peirceana por Plaza (2003), 
para darmos novos desdobramentos a essa noção. Ancorados na semiótica discursiva, buscamos compreender o quanto as coerções das linguagens postas em jogo em uma adaptação podem influenciar no seu resultado. Em outras palavras, propomos um exame, na passagem de um sistema semiótico a outro, de como as estratégias de textualização adotadas na linguagem de partida são transpostas para a linguagem de chegada. Dessa maneira, essa perspectiva teórico-metodológica permite uma análise simultânea da tradução como produto e como processo. Produto, entendida como um todo de significação resultante da articulação entre plano de conteúdo, composição discursiva, plano de expressão e materialidade significante, que manifesta o plano de conteúdo (cf. FIORIN, 2011). Processo, com foco na instância da enunciação, ato de produção do discurso. Desfaz-se, assim, o tradicional tratamento dicotômico dado às duas dimensões, amplamente discutidas nos estudos de tradução e de adaptação. Como em Hutcheon (2013), que toma a adaptação ora como produto ou "entidade formal", ora como processos "de criação" e "de recepção".

Para a semiótica discursiva, na passagem de um sistema semiótico a outro, o que se traduz é um projeto enunciativo (cf. MANCINI, 2018), conjunto de estratégias utilizadas pelo enunciador: "eu”, que diz - no processo de textualização, visando otimizar seu fazer persuasivo em relação ao fazer interpretativo de um enunciatário; "tu", a quem se dirige - que ele prevê no próprio modo de enunciar. Cabe elucidarmos que enunciador e enunciatário não são autor e leitor reais, mas perfis depreendidos do texto (cf. FIORIN, 2004). Dessa forma, a tradução intersemiótica é concebida como a recriação de um projeto enunciativo em outro, que visa à construção de um simulacro de aproximação à primeira enunciação no texto de chegada, considerando seu novo perfil de enunciatário e as diferenças das linguagens em jogo.

É no espectro desse simulacro de proximidade que situamos a questão da fidelidade. Para nós, importa observar se o tradutor foi "fiel" ao projeto enunciativo de partida. Nesse caso, a concepção de fidelidade se relativiza, podendo ser tomada como um horizonte de comparação mais profundo ou como um elemento intrínseco ao projeto enunciativo de chegada - quando uma obra se vende como adaptação fiel. Em nossa abordagem, a figura do tradutor/adaptador também assume um duplo papel, sincretizando um fazer interpretativo e um fazer persuasivo: ele atua como enunciatário do primeiro texto e como enunciador do segundo, o que teóricos da tradução e da adaptação chamam de intérprete e de autor, respectivamente.

As questões da fidelidade e da função do tradutor/adaptador se associam a outra reflexão recorrente, acerca da definição de tradução como criação e como crítica. No que diz respeito à ideia de criação, referindo-se à poesia, Campos (1976, p. 24) afirma que a "tradução de textos criativos será sempre recriação, ou criação paralela, autônoma porém reciproca. Quanto mais inçado de dificuldades esse texto, mais recriável, mais sedutor enquanto possibilidade aberta de recriação". A noção de crítica, por sua vez, relaciona-se ao fato da atividade de tradução pressupor um movimento metalinguístico. Em resumo, por envolver uma depreensão inicial de efeitos de sentido pelo tradutor-enunciatário e uma posterior reconstrução desses efeitos pelo tradutor-enunciador, uma adaptação inevitavelmente implica mudanças.

Porém, a adaptação caracteriza-se também como uma "repetição com variação", como "o conforto do ritual combinado com uma pitada de surpresa" (HU- 
TCHEON, 2013, p. 4). Isso quer dizer que esse potencial criativo será sempre circunscrito por um modo de uso já estabilizado das linguagens postas em jogo. Assim, tem-se a tradução intersemiótica como um exercício de adequação a diferentes formas de vida, estilos e comportamentos sedimentados em uma cultura, que instauram regimes de crença duráveis, resultantes do emprego reiterado de conjuntos de estratégias na articulação de práticas semióticas entre si. Como define Fontanille (2015, p. 14),

[...] as formas de vida são organizações semióticas ("linguagens") características de identidades sociais e culturais, individuais e coletivas, [...] constituem verdadeiras semióticas-objetos, dotadas de um plano de expressão e de um plano de conteúdo, e suscetiveis de funcionar de maneira autônoma no seio da semiosfera.

A noção de semiosfera citada pelo autor foi cunhada por Lotman (1996) e pode ser pensada como um modo de funcionamento das formas de vida. A semiosfera é um espaço semiótico que abriga as construções culturais. É homogênea na medida em que se constitui como um todo coeso, definido em relação a outra semiosfera, mas também envolve certa heterogeneidade, uma vez que é composta por estruturas conflitantes. Essas estruturas distribuem-se em um continuum e estão em constante dinamismo, movendo-se entre o centro, mais estável - em que se organizam os sistemas semióticos dominantes - e a periferia, menos estável. Nas margens da semiosfera, atua uma fronteira, divisor abstrato e imaginário que separa uma semiosfera de outra, mas também as une, permitindo a troca de informações entre elas. É um mecanismo por meio do qual elementos a princípio "alheios" são selecionados, filtrados e adaptados para a linguagem da semiosfera em questão. Lotman chama esse processo de tradução.

A partir desses conceitos, nesta pesquisa, concebemos as linguagens jornalística e quadrinística como duas formas de vida, cada uma constituindo uma semiosfera. Estas mobilizam regimes de crença que criam, de um lado, um universo factual e, de outro, um ficcional. É na zona fronteiriça entre elas que surge o jornalismo em quadrinhos, resultado de um movimento de tradução. Porém, no caso do JQ, esse movimento transcende a recriação de um projeto enunciativo em outro, sob novas coerções, já que não há obra de partida. Trata-se, na verdade, de um contato entre dois conjuntos de práticas estabilizadas. A nossa proposta é a de que a prática semiótica, enquanto gesto enunciativo, quando reiterada, estabiliza e cristaliza um modo prototípico de dispor expressão e conteúdo, que se sedimenta em uma "linguagem". Assim, no JQ, busca-se recriar não apenas elementos de uma obra em outra, mas também de uma linguagem em outra. O que está em jogo é um processo de neutralização de diferenças entre linguagens, o que nos encaminha para a discussão sobre o hibridismo.

\section{ParÂMetros de ANÁlise}

Feita essa breve teorização do conceito de tradução intersemiótica, partimos para o estabelecimento de um protocolo genérico de ações para a análise do fenômeno, neste artigo, aplicado à reportagem em quadrinhos $O$ fim, do jornal Extra. Inicialmente, quanto ao plano de conteúdo, atemo-nos aos recobrimentos semânticos, identificando que temas e figuras podem se manter, desaparecer ou 
surgir no texto de chegada. Os temas são termos mais abstratos, com função de explicar e interpretar o mundo, e as figuras, termos mais concretos, que simulam e descrevem o mundo (cf. FIORIN, 2011). Em nosso caso, como não há um texto de partida, tomamos como base comparativa o que é recorrente nas coberturas jornalísticas tradicionais. Examinamos também como se dá a projeção das categorias de pessoa, tempo e espaço, criando efeitos de aproximação ou de distanciamento da instância da enunciação (cf. FIORIN, 2005). Consideramos, ainda, a organização narrativa do texto, observando os programas narrativos e seus arranjos e como estes se relacionam. Denomina-se programa narrativo "o sintagma elementar da narrativa, que integra estados e transformações, e que se define como um enunciado de fazer que rege um enunciado de estado" (BARROS, 2005, p. 84).

Em seguida, debruçamo-nos sobre o plano de expressão, conforme propõe Floch (1985), analisado com base em uma descrição de seus componentes baseada nas categorias cromática (cores), eidética (formas), topológica (posição e orientação no espaço) e matérica (corporalidade e materialidade). A variedade do plano de expressão é um elemento-chave no estudo da tradução intersemiótica, colocando-se como um grande desafio na reconstrução, em uma adaptação, dos efeitos de sentido da linguagem de partida. É importante avaliar quais planos de expressão são pertinentes a cada objeto. Como explica Fiorin (2011, p. 45), ao citar a adaptação do romance Vidas secas, de Graciliano Ramos composto unicamente por um plano de expressão verbal - para o filme homônimo - em que se sobrepõem os planos de expressão visual, verbal e musical:

Mas poderia alguém objetar: quando se veicula um conteúdo por meio de distintos planos de expressão, esse conteúdo sofre certas alterações. É verdade. Essas mudanças no conteúdo decorrem basicamente de dois fatores: os efeitos estilísticos da expressão e as coerções do material.

A análise de uma tradução intersemiótica deve, finalmente, levar em conta o processamento do texto de chegada pelo enunciatário, seus modos de adesão e interação, entendidos como interfaces sensiveis e inteligiveis do ato perceptivo. Recorremos, então, à abordagem tensiva da semiótica para um exame dos diferentes regimes sensoriais e passionais propostos pelo enunciador-tradutor. Tal desdobramento introduz na teoria a ideia de gradação, propondo "uma sintaxe que visa a dar conta dos movimentos e inflexões que servem de base para a construção discursiva" (MANCINI; TROTTA; SOUZA, 2007, p. 296). Com isso, torna-se possivel a identificação de um ritmo do discurso, regido por uma pulsação da interlocução criada pela tensão contínua entre as dimensões da intensidade - os estados de alma, o sensivel - e da extensidade - os estados de coisas, o inteligivel (ZILBERBERG, 2011, p. 66). A intensidade concerne à força da percepção, da tensão entre sujeito e objeto. A extensidade delimita a amplitude do campo de presença do sujeito, sua arena perceptiva. Com essa abordagem, pode-se, por exemplo, investigar se os momentos de saliência perceptiva da linguagem de partida são mantidos na de chegada.

A aplicação, em diferentes objetos, do protocolo de ações que acabamos de apresentar tem nos permitido pensar em tipos gradativos de traduções intersemióticas. Traçando um continuum, podemos situar em um extremo obras que prezam por uma adaptação de conteúdo, como nos parece ser o caso de A Cartomante em quadrinhos (cf. GOMES, 2015) e de outras HQs que adaptam clássicos 
da literatura. No polo oposto, localizamos trabalhos que buscam a construção de um produto híbrido, concebido por uma enunciação sincrética que neutraliza as fronteiras existentes entre as linguagens postas em jogo. Trata-se da "transformação de uma alternância em uma coexistência” (ZILBERBERG, 2011, p. 34), dando origem a um termo complexo, em que as linguagens se tornam indissociáveis. Um exemplo é a adaptação da novela gráfica Sin City, de Frank Miller, para o filme homônimo, objetos analisados por Mancini (2008). Motivados por esses resultados, esperamos também identificar a posição do jornalismo em quadrinhos nessa gradação. Mas, antes da análise de $O$ fim, cabe uma descrição dos principais componentes das linguagens jornalística e quadrinística.

\section{As LiNGUAgens EM JOGO}

[...] é natural que a tentativa de transportar os gêneros e as práticas tradicionais do jornalismo para um meio aparentemente tão inadequado provoque uma sensação de estranhamento e suscite a questão óbvia: como uma série de vinhetas desenhadas, que remetem facilmente àquelas primeiras histórias lidas na infância, pode almejar constituir uma narrativa verossimilhante e ancorada na realidade? (NECO, 2010, p. 21).

Indagações semelhantes à de Neco norteiam grande parte dos estudos e debates sobre o jornalismo em quadrinhos. Partimos também desse questionamento para compreender em maior profundidade porque a viabilidade desse tipo de transposição entre linguagens é tão comumente posta em dúvida. Debrucemonos, então, sobre alguns dos principais elementos entendidos como caracterizadores das linguagens jornalística e quadrinística, devido à repetição e à regularidade de seus usos, que nos permitem um reconhecimento imediato de cada uma delas. Dessa maneira, conseguimos identificar em que aspectos essas linguagens mais se diferenciam.

Ao referir-se ao texto jornalístico como "uma narrativa verossimilhante e ancorada na realidade", Neco retoma a discussão sobre a pretensa vocação do jornalismo para a representação fiel e verdadeira dos fatos (GOMES, 2008, p. 69-70). Tal crença se constitui com base na adoção recorrente pelos jornais de um conjunto de estratégias visando à manutenção dos efeitos de objetividade e de realidade. O uso da terceira pessoa, debreagem enunciva actancial, é um desses procedimentos. O mecanismo mantém a enunciação afastada do discurso, criando um simulacro de distanciamento.

Finge-se distanciamento da enunciação, que, dessa forma, é "neutralizada" $e$ nada mais faz que comunicar os "fatos" e o modo de ver de outros. Além de produzir efeito de verdade objetiva, o jornal, com a aparência de afastamento, evita arcar com a responsabilidade do que é dito, já que transmite sempre a opinião do outro, o saber das fontes (BARROS, 2005, p. 55).

A delegação de voz é outro recurso comum na linguagem jornalística, expresso pelo emprego do discurso direto, o que chamamos de debreagem interna. A estratégia é utilizada para apresentar várias opiniões discordantes, diferentes versões e interpretações dos fatos. Assim, constrói-se uma ideia de "cobertura completa" e atribui-se ao outro a responsabilidade discursiva. A debreagem interna cria, ainda, um efeito de sentido de realidade. Barros (2005, p. 57) esclarece que: 
O jornal [...] utiliza a delegação do saber com um duplo efeito, o de objetividade e o de "dono da verdade". Seu discurso transmite, com "imparcialidade", o saber de várias "fontes", e o jornalista-observador congrega o conhecimento de todas elas e obtém, assim, a verdade ilimitada e absoluta.

O efeito de sentido de realidade também é construído por meio do procedimento da ancoragem, a concretização dos atores, tempos e espaços do discurso. A ancoragem, no limite, resulta de uma iconização, "o investimento figurativo exaustivo final, isto é, a última etapa da figurativização, com o objetivo de produzir ilusão referencial" (BARROS, 2005, p. 69). Nesse caso, temos o enunciador do jornal utilizando-se ao máximo de figuras, a fim de levar o enunciatário a reconhecer imagens do mundo natural projetadas no texto e, a partir daí, crer na verdade do discurso. Quanto mais figurativizado o texto, maior o efeito de sentido de realidade criado.

À verossimilhança e à ancoragem atribuídas como típicas ao jornalismo, Neco (2010) opõe as "vinhetas desenhadas" das HQs. Com isso, o autor evidencia a importância da especificidade do plano de expressão dos quadrinhos em sua caracterização como linguagem. Entre seus principais constituintes, podemos citar: os quadros, também chamados de vinhetas ou de quadrinhos, segmentos sequenciados que encapsulam um momento do fluxo narrativo; os requadros, molduras dos quadros, que exercem diversas funções e constroem diferentes efeitos de sentido segundo seu formato (ou por sua ausência) - por exemplo, a marcação de flashback indicada por um traçado sinuoso ou ondulado; as calhas, ou sarjetas, espaços entre os quadros; a variada tipologia de balões de fala, que também constroem efeitos de sentido distintos de acordo com as suas configurações; os rabichos, apêndices que se alongam para fora dos balões, indicando quem fala; os recordatórios, painéis que abrigam a narração; as linhas cinéticas, traços que indicam movimento; as onomatopeias etc. (EISNER, 2010; SANTOS, 2015).

As linguagens jornalística e quadrinística se distinguem, ainda, pelos modos de adesão e de interação que propõem. Aqui, recorremos à abordagem tensiva da semiótica, mais especificamente ao conceito de andamento, "senhor, tanto de nossos pensamentos, quanto de nossos afetos, dado que ele controla despoticamente os aumentos e as diminuições constitutivas de nossas vivências" (ZILBERBERG, 2006, p. 168). O andamento é uma das subdimensões da intensidade esta, como vimos, concernente ao universo sensivel, que rege o inteligivel - e pode assumir uma direção de aceleração ou de desaceleração. De acordo com essas inflexões, imprime-se um ritmo de leitura no texto. A partir dessa noção, podemos definir, comparativamente, um perfil rítmico para a linguagem jornalística e um para a quadrinística. Dizemos, então, que a primeira se caracteriza por um perfil aspectual, um elã, da lentidão e, a segunda, da rapidez.

Identificamos no jornalismo, pensado canonicamente, um andamento mais lento em uma confrontação com os quadrinhos, uma vez que a atividade privilegia a inteligibilidade na veiculação dos conteúdos. Como vimos discutindo, os jornais evitam deixar brechas para desvios de interpretação, buscando fornecer informações precisas e apresentar os fatos narrados sob seus diversos ângulos. Também mantêm certa previsibilidade, explicitada pela construção de uma identidade visual; no caso da mídia impressa, pela padronização da diagramação; pela escolha vocabular; pela recorrência de temas e de pontos de vista no 
noticiário; entre outros procedimentos. Por conta disso, encaminham um percurso mais linear de leitura, atendendo a determinadas expectativas, o que desenha um ritmo mais lento de interação.

Os quadrinhos são mais rápidos, visto que são ricos em hipérboles e em sobreposições visuais e verbais; possuem um ritmo de leitura mais entrecortado, imprevisível e dinâmico - em alguns casos, inclusive, rompendo com a convenção da sequência de leitura da esquerda para a direita (EISNER, 2010, p. 2); abstêm-se do excesso de narração; e demandam o preenchimento de muitas lacunas de sentido, as chamadas catálises. Mancini e Alt (2013, p. 104) explicam que a agilidade de leitura é "um modo constitutivo de interação do leitor com as histórias em quadrinhos. Gera uma expectativa, uma predisposição cognitiva e sensorial à celeridade, um hábito da rapidez".

\section{“O Fim" do Complexo do AlemÃo}

Após o detalhamento de uma identidade mais abrangente das duas linguagens postas em jogo no jornalismo em quadrinhos, encaminhamo-nos para a análise da reportagem em quadrinhos $O$ fim - O dia em que a bandidagem do Rio perdeu a fama de valente, publicada pelo jornal carioca Extra, em 24 de novembro de 2011, um ano após a ocupação dessas favelas pelas forças de segurança do Estado do Rio de Janeiro. Quando a matéria saiu, o jornal era o terceiro maior impresso do Brasil de circulação paga, por ano, e o primeiro do Rio de Janeiro (ASSOCIAÇÃO NACIONAL DE JORNAIS - ANJ, 2011). Assim, o trabalho ganhou grande repercussão entre o público. A reportagem em quadrinhos foi veiculada em uma revista em formato tabloide, com 16 páginas coloridas. $\mathrm{O}$ suplemento foi distribuído gratuitamente aos leitores, encartado no jornal, na época vendido a $\mathrm{R} \$ 1,10$. Com roteiro de João Arruda e desenho de Allan Alex, O fim envolveu 13 profissionais, durante 47 dias. Na contracapa da revista, o Extra enfatiza a grandiosidade do trabalho realizado:

Oitenta e nove personagens, entre autoridades, policiais, militares, suspeitos de ligação com o tráfico e moradores, foram entrevistados. Os repórteres leram 630 páginas de processos, documentos e rascunhos, gravaram 74 horas de vídeo e áudio, fizeram 257 fotos, checaram, rechecaram e cruzaram depoimentos para chegar à versão mais fiel do que aconteceu naqueles oito dias de novembro (O FIM, 2011, p. 2).

O Complexo do Alemão é formado por 13 favelas e localiza-se na Zona Norte do Rio de Janeiro. Próximo a ele, fica a favela Vila Cruzeiro, também alvo da operação das forças de segurança. Conforme dados da reportagem analisada, até 2011, as duas regiões abrigavam 103 mil pessoas, morando em 30.750 casas espalhadas por 3.750.000 metros quadrados. Tomados em conjunto, os dois territórios eram considerados as maiores favelas do Rio de Janeiro (cf. O FIM, 2011). A ocupação foi motivada por uma sequência de ações violentas iniciadas em 21 de novembro de 2010, lideradas pelo Comando Vermelho - facção criminosa que chefiava as duas regiões -, como incêndios de carros e ônibus, ataques a forças de segurança e arrastões. A operação se deu em duas etapas, com a entrada na Vila Cruzeiro, em 25 de novembro, e no Complexo do Alemão, no dia 28. O Extra qualificou o episódio como "a maior operação militar de tomada de território na história recente do país” (O FIM, 2011, p. 2). 
Começamos a análise com a capa do Extra de 24 de novembro de 2011 (Figura 1). O jornal surpreendeu o público ao combinar elementos cristalizados como constituintes das linguagens jornalística e quadrinística. A página traz o logo do veículo na parte superior; um selo promocional; o preço; o título e a chamada da manchete do dia - que, curiosamente, é sobre a reportagem em quadrinhos -, acompanhados de uma imagem central; e chamadas menores, das editorias de cidade, entretenimento e economia. Há, ainda, informações sobre uma promoção em andamento, sobre o favoritismo do jornal entre os leitores e sobre o número de páginas da edição. Tudo configurado topologicamente em uma diagramação que não foge ao canônico. Porém, as fotografias dão lugar a ilustrações e o conteúdo verbal é expresso por fontes com designs semelhantes aos das usadas nas HQs. Até o logo do Extra recebe tratamento visual diferenciado, o que não acontece apenas com o selo promocional.

Figura 1 - Capa do jornal Extra, de 24 de novembro de 2011

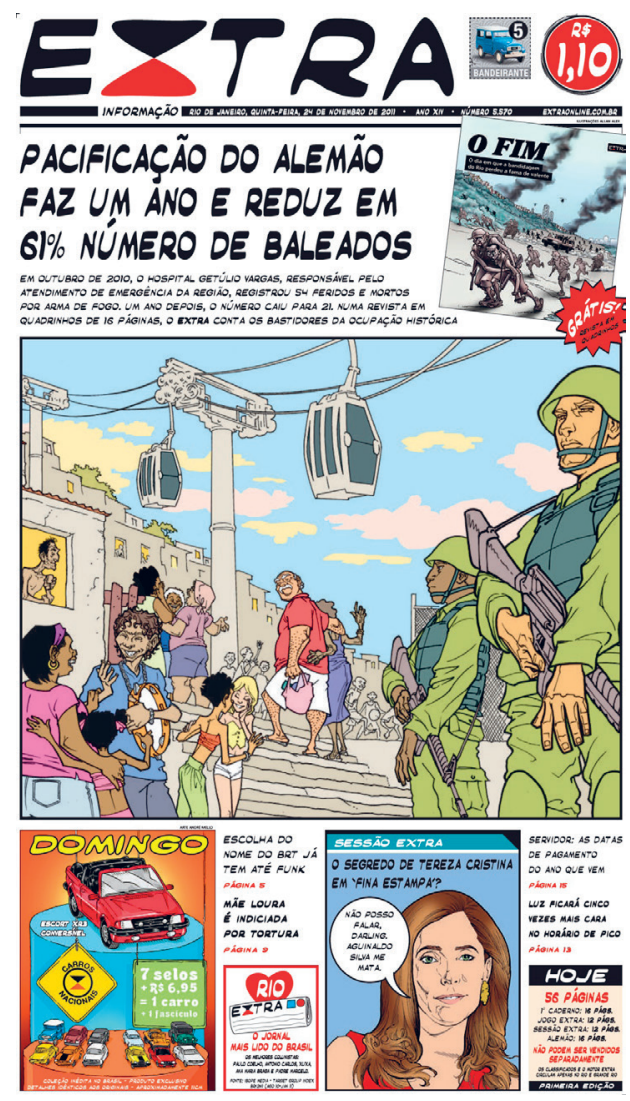

Outro recurso dos quadrinhos usado na página é o balão de fala, que delega voz à personagem Tereza Cristina, da novela Fina Estampa, passível de ser reconhecida pela chamada, pela construção figurativa da mulher e pelo jargão "darling" - característica marcante da constituição da personagem na trama. Em 
uma capa convencional, o procedimento possivelmente se daria pelo uso do discurso direto inserido entre aspas em uma legenda. Além disso, não é comum aos jornais dar voz a figuras ficcionais. Seria mais provável a presença de uma fala da atriz que interpreta o papel em questão, Christiane Torloni. Esse jogo entre os universos ficcional e factual, aliado ao arranjo entre os demais elementos citados, leva a capa do Extra a caminhar em direção a um hibridismo, processo em que, como vimos, neutralizam-se as fronteiras entre as linguagens envolvidas em uma adaptação.

A capa da revista em quadrinhos (Figura 2) organiza-se de maneira diferente. Uma ilustração ocupa toda a extensão da página, sobreposta pelo título e pelo subtítulo da reportagem e por um pequeno logo do Extra - aqui expressos em tipografias comumente usadas pelos jornais. O fim, em negrito, caixa alta e fonte ampliada, euforiza o resultado da operação executada pelas forças de segurança, que, conforme enfatiza o subtítulo, com base em um contraste estabelecido entre fundo preto e fonte branca, levou a "bandidagem do Rio" a perder "a fama de valente". Com isso, tem-se na capa a explicitação de um julgamento e de um envolvimento passional em relação ao episódio narrado. Conforme salienta Gomes (2008, p. 35), esse tipo de estratégia, em conjunto com o emprego de uma linguagem coloquial, oralizada, marcada pelo uso de gírias e, no limite, de expressões vulgares, caracteriza os jornais ditos "populares". Sublinhamos que o coloquialismo se mantém durante toda a reportagem em quadrinhos.

Figura 2 - Capa de O fim - O dia em que a bandidagem do Rio perdeu a fama de valente

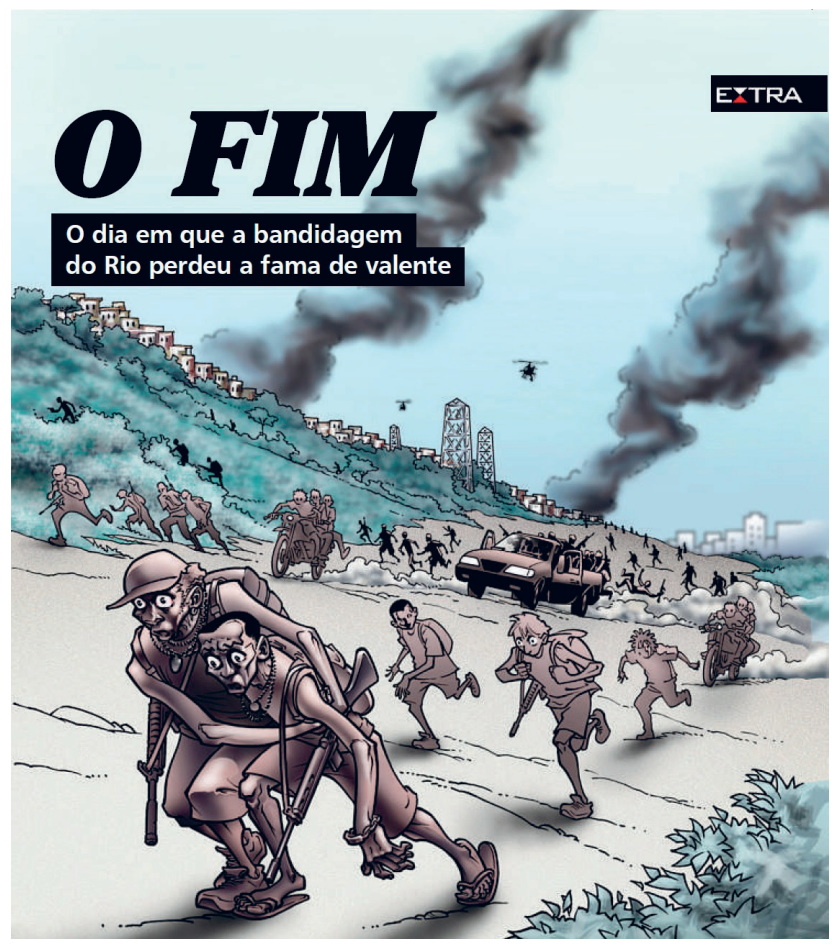


A ilustração que estampa a primeira página da reportagem em quadrinhos é uma representação das famosas cenas gravadas de um helicóptero da Rede Globo da fuga de criminosos da Vila Cruzeiro, em 25 de novembro de 2010. Elas se tornaram um simbolo da cobertura jornalística da ocupação. Enquanto, na capa, as imagens assumem um estilo mais cartunesco, ao longo da reportagem, reaparecem de forma icônica, em frames da transmissão ao vivo feita na época pelo $R J T V$ (Figura 3). Esses frames são inseridos de modo a se imbricarem aos desenhos das televisões, um esforço de conciliação entre as duas linguagens em jogo. Também é reproduzida, em balões, a interlocução entre os repórteres Márcio Gomes e Ana Paula Araújo e o ex-capitão do Bope e comentarista de segurança Rodrigo Pimentel. A adoção dessas estratégias está a serviço da construção do efeito de sentido de verdade que permeia o fazer jornalístico.

Figura 3 - Reprodução da transmissão da Rede Globo da fuga da Vila Cruzeiro

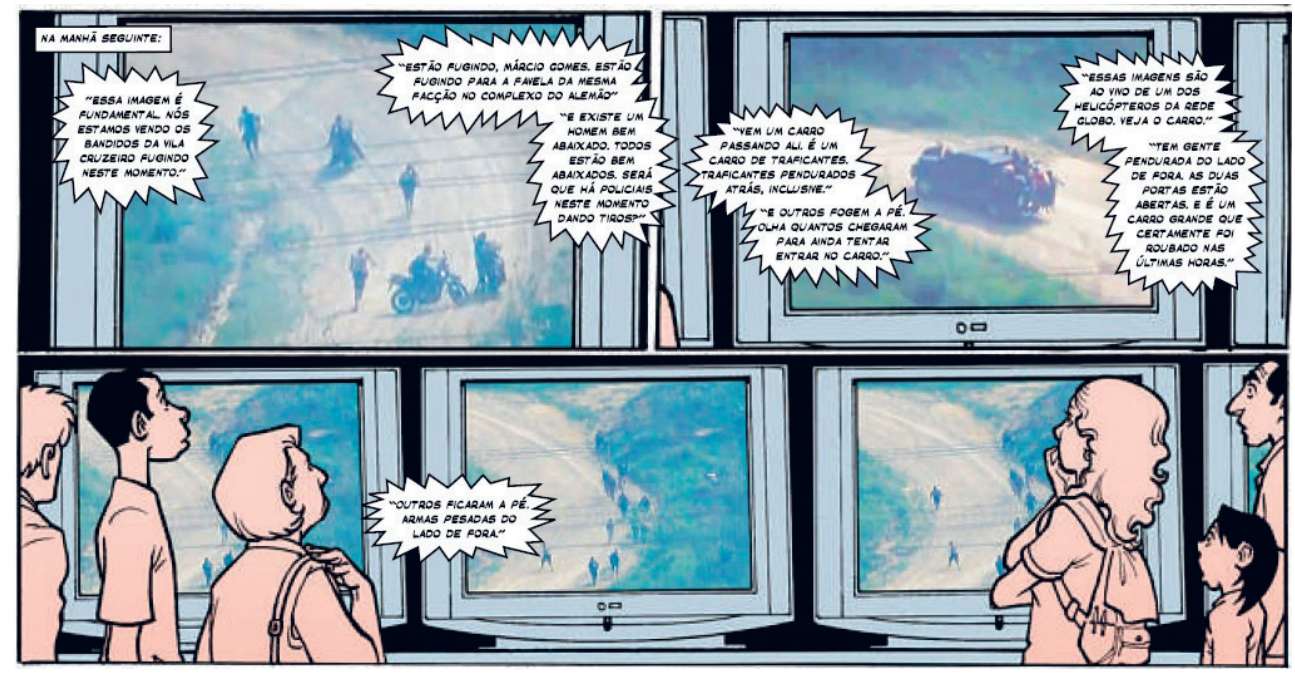

Fonte: O fim (2011, p. 6).

Direcionamos nosso olhar agora para a contracapa de O fim (Figura 4). Enquanto a primeira página do Extra de 24 de novembro de 2011 já convida os leitores a entrarem em contato com a linguagem quadrinística, proposta que perdura na capa da reportagem em quadrinhos, a contracapa promove um rompimento no ritmo de leitura mais acelerado inerente às HQs. Deparamo-nos com duas frases em destaque, três reproduções de edições do Extra de 2010 referentes à cobertura da ocupação e um grande bloco de conteúdo verbal, distribuído em colunas, diagramação comum à mídia impressa. É um editorial, que traz alguns dos números que apresentamos no início deste tópico, sobre as favelas, a operação e a empreitada do Extra para a elaboração da matéria. Logo abaixo, um expediente lista os nomes e e-mails dos profissionais que participaram da execução do projeto, como de praxe nas contracapas dos jornais. 
Figura 4 - Contracapa de $O$ fim, com editorial e expediente

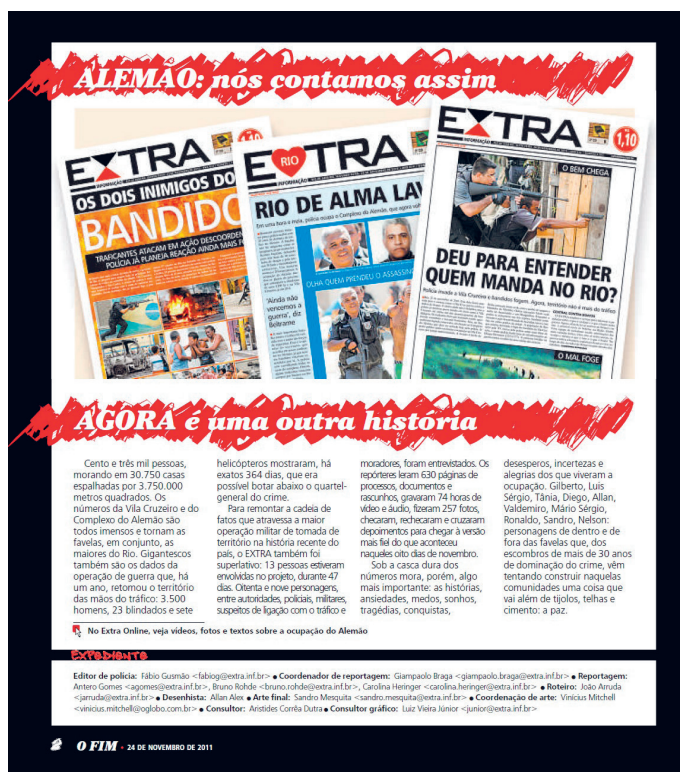

Fonte: $O$ fim $(2011$, p. 2).

No editorial, o Extra euforiza mais uma vez a operação, a partir da exposição de seus números exorbitantes e ao afirmar que as forças de segurança "mostraram [...] que era possivel botar abaixo o quartel general do crime" (O FIM, 2011, p. 2). Também é abordado o impacto da ocupação na vida de pessoas envolvidas no cotidiano do Complexo do Alemão e da Vila Cruzeiro. Algumas são, inclusive, nomeadas, chamadas apenas pelo prenome, o que estabelece uma relação mais intima, de proximidade. São adotadas estratégias discursivas que constroem um forte apelo emocional.

Ainda em relação ao editorial, cabe observarmos também como a fidelidade é posta em relevo pelo Extra. Seu título constrói uma oposição entre a cobertura feita em 2010, adotando a linguagem jornalística tradicional, e a reportagem em quadrinhos publicada em 2011. Na primeira linha, a frase "ALEMÃO: nós contamos assim" (O FIM, 2011, p. 2) refere-se às capas das edições antigas do jornal, posicionadas logo abaixo. Já na segunda, a frase "AGORA é uma outra história" (O FIM, 2011, p. 2) apresenta o editorial e a matéria que se desenrola a partir da página seguinte. Mas, se por um lado, o enunciador faz questão de distinguir os dois trabalhos, ao longo do editorial, por outro, torna-se explícita uma preocupação em enfatizar que o Extra procura "remontar a cadeia dos fatos [...], para chegar à versão mais fiel do que aconteceu” (O FIM, 2011, p. 2, grifo nosso). Há então, ao mesmo tempo, um reconhecimento da adaptação como um novo texto, como recriação, e uma demarcação da fidelidade como elemento intrínseco ao seu projeto enunciativo.

Examinada a contracapa de $O$ fim, retomamos a questão do ritmo de leitura para destacarmos um segundo momento, em nosso objeto de análise, de quebra abrupta do andamento acelerado da linguagem quadrinística. Aproximadamente no meio da reportagem do Extra, as ilustrações, quadros, requadros, calhas, 
balões, rabichos e recordatórios cedem espaço a um imenso infográfico (Figura 5), que ocupa duas páginas da revista. Com o uso do recurso, novamente, a rapidez dos quadrinhos sofre uma desaceleração - ainda que, no âmbito da linguagem jornalística, o infográfico seja um elemento condensador de conteúdo, mais rápido do que uma apresentação verbal. Intitulado "A retomada da Vila Cruzeiro e do Complexo do Alemão", o material detalha a operação, com informações sobre as duas regiões em questão - área, número de domicílios e população -, as armas e veículos utilizados, as forças de segurança acionadas, a estratégia adotada para o acesso às favelas, os resultados - entre prisões e apreensões - e uma cronologia - do dia 21 de novembro de 2010, quando começou a sequência de ações violentas lideradas pelo Comando Vermelho, até o dia 28, data da ocupação do Complexo do Alemão. Quanto à composição visual, constituem o infográfico um mapa das favelas, fotos borradas de helicópteros, blindados e agentes de segurança armados e, em menor destaque - no canto inferior direito -, fotos também borradas de criminosos armados. Todos os homens têm rostos indefinidos.

Figura 5 - Infográfico de $O$ fim, com detalhamento da operação e cronologia

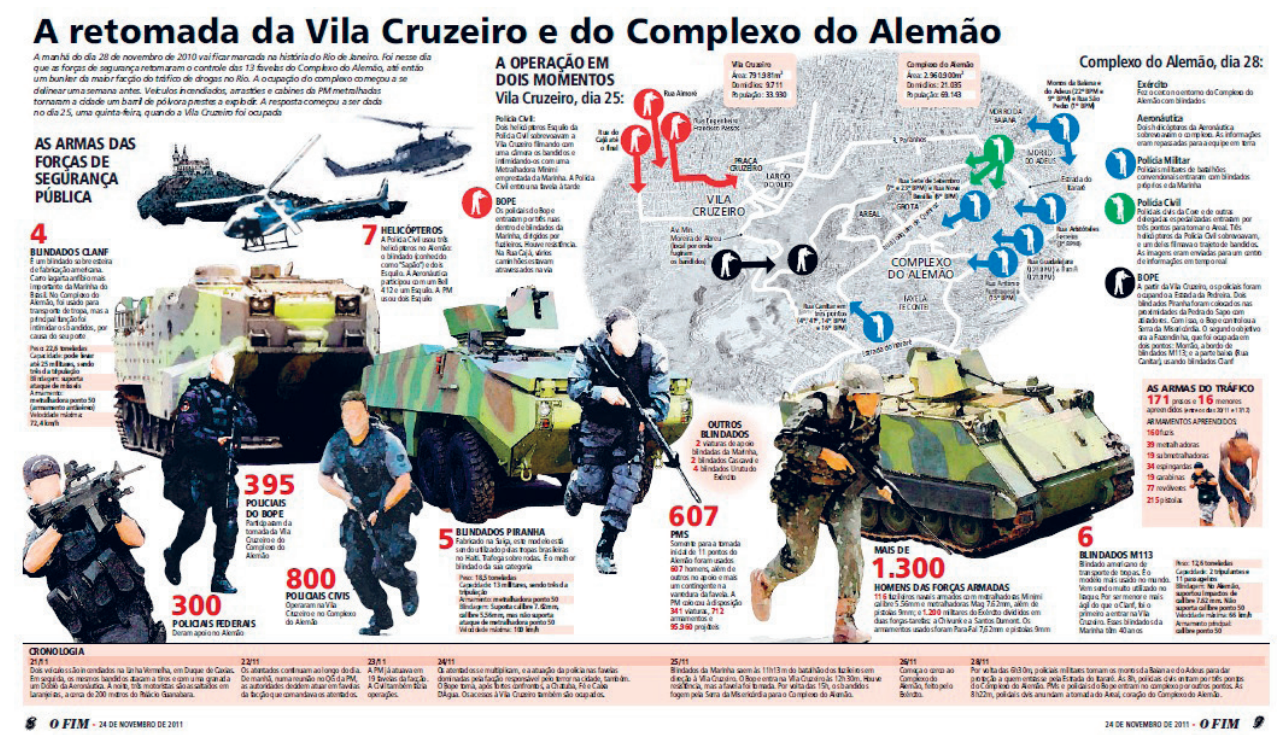

Fonte: O fim (2011, p. 8-9).

Como percebemos, o infográfico dá ênfase à organização da operação e, ainda que com um destaque menor, também expõe seus resultados. É essa a estratégia discursiva que norteia a reportagem em quadrinhos aqui analisada. $\mathrm{O}$ foco de $O$ fim é, sobretudo, contar minuciosamente como se arquitetou a ocupação do Complexo do Alemão e da Vila Cruzeiro e, adicionalmente, traçar um panorama dessas comunidades um ano após o ocorrido. São recorrentes ao longo da matéria os temas da (in)segurança, da violência e do medo, que perpassam a trajetória de todos os envolvidos no episódio, representantes do governo, forças de segurança, moradores, criminosos e suspeitos.

Autoridades federais e estaduais e agentes da segurança pública e das Forças Armadas ganham grande destaque. Eles são representados visualmente em 
praticamente todas as páginas, figurativizados pelas ilustrações. O enunciador recorre a construções visuais icônicas para representar alguns deles, os nomes mais conhecidos na cena política brasileira relacionados com a ocupação, como o Secretário de Segurança do Rio de Janeiro, José Mariano Beltrame, o então governador Sérgio Cabral e o ex-presidente Lula (Figura 6). Além de fortalecer a presença desses atores no texto, a estratégia produz efeito de realidade, um dos pilares do jornalismo.

Figura 6 - Lula em $O$ fim

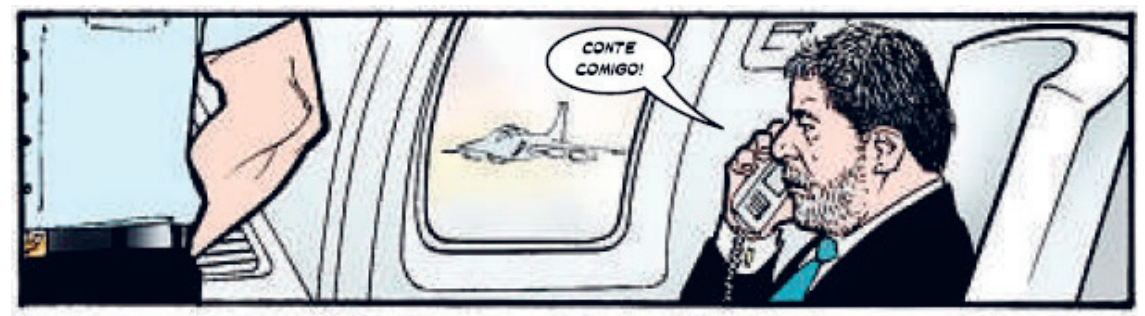

Fonte: O fim (2011, p. 4).

Além disso, grande parte das interlocuções presentes na reportagem envolvem tais atores. Por meio dos balões de fala, são apresentados diálogos breves que marcaram os bastidores da operação, a maioria, contatos telefônicos, para negociações, orientações ou ordens. Em um deles, por exemplo, o Ministro da Defesa na época, Nelson Jobim, pergunta a Lula se deve ir adiante ou não com o plano de entrar na Vila Cruzeiro, ao que o ex-presidente responde que irá colaborar (O FIM, 2011, p. 4). Já nos recordatórios, o narrador delega voz a cabos, inspetores, comandantes e delegados, que dão seus depoimentos sobre o episódio. Como o testemunho do então comandante-geral da PM, Mário Sérgio Duarte: "explicamos ao governador que a ideia era incitar a rendição como uma estratégia psicológica, para que eles entendessem a estupidez que seria resistir" (O FIM, 2011, p. 11). Tais falas são indicadas nos recordatórios por aspas.

Ainda com referência às autoridades e às forças de segurança, notamos que o Extra, embora claramente atribua um valor eufórico à ocupação em alguns momentos - como no título da reportagem e no editorial, conforme vimos -, também narra fatos relacionados ao episódio de modo a contribuir para a construção de uma valoração disfórica desses atores. Em uma sequência de quadros que narra as primeiras ocorrências de incêndios a veículos no município do Rio de Janeiro e os movimentos iniciais da PM para combater essas ações, por exemplo, o narrador indica: "[...] bandidos morreram, suspeitos foram presos, armas apreendidas. O Rio continuava pegando fogo. E a policia estava perdida" (O FIM, 2011, p. 3, grifo nosso). Mais adiante, em uma passagem sobre o hasteamento da bandeira da Polícia Civil no lugar da do Estado do Rio de Janeiro, temos a seguinte narração, referente ao então chefe da corporação: "[Allan] Turnowski tinha a impressão de que ia ser fuzilado com os olhos pelo comandante da PM e por Beltrame. Depois de entrar primeiro no Alemão, a Polícia Civil tinha dado outra volta na PM" (O FIM, 2011, p. 13, grifo nosso). O tema da corrupção também ganha visibilidade: “após a ocupação, o Alemão se transformou 
num garimpo. Policiais da banda podre voltaram sorrateiramente à noite para cavar dinheiro, drogas e armas. O chamado espólio de guerra" (O FIM, 2011, p. 14, grifo nosso).

É importante mencionarmos, ainda, a especificidade da construção figurativa feita pelo enunciador do então governador Sérgio Cabral. Uma postura informal, cômica e irônica é reafirmada ao longo da reportagem, a partir do uso de recursos dos planos de conteúdo e de expressão. Na narração de uma discussão com o ex-comandante-geral da PM, Mário Sérgio Duarte, sobre a possibilidade de oferecer a chance de rendição aos criminosos, é atribuída ao chefe de governo a seguinte fala: "você acha que se botar alguém com uma faixa de 'welcome', vai chover bandido querendo se entregar?" (O FIM, 2011, p. 11). Sobre a confusão da troca das bandeiras da Polícia Civil e do Estado do Rio de Janeiro, o interlocutor Cabral diz ao então chefe da Polícia Civil, Allan Turnowski: "Allan, ficou até melhor" e, ao delegado Rodrigo Oliveira, que estava à frente do caso, "parabéns! você quer almoçar o quê?". Em outro quadro, o ex-governador é retratado ouvindo um trecho de uma música de Martinho da Vila, "...quando essa onda passar / Formiga, Borel ou Salgueiro...”, enquanto comemora com Lula pelo telefone: "Formiga, pacificado! Borel, pacificado! Salgueiro, pacificado! Golaço, Lula! Golaço, Lula!”. A fala se encerra com um xingamento, expresso no balão por símbolos, como de costume na linguagem quadrinística (Figura 7). As expressões corporais de Cabral reiteram o caráter informal, cômico e irônico atribuído a ele.

Figura 7 - Cabral em conversa telefônica com o ex-presidente Lula

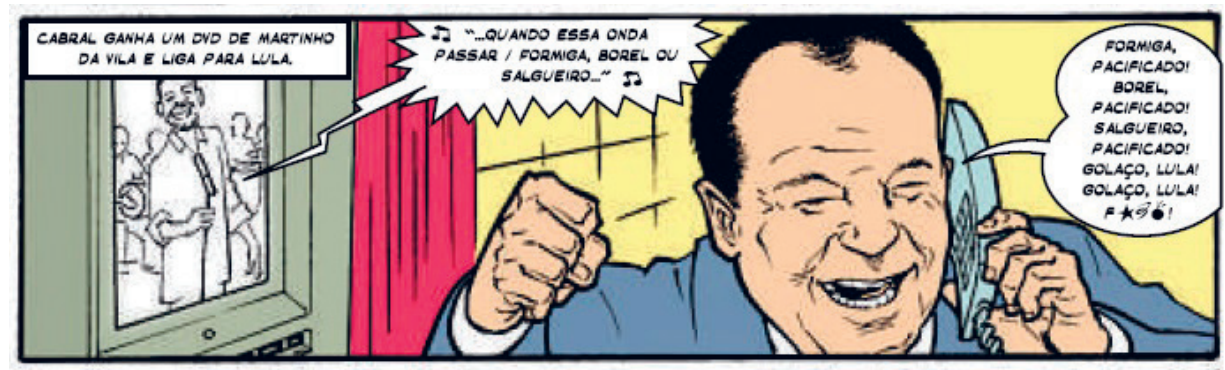

Fonte: O fim (2011, p. 14).

Além de apresentar ao público a versão das autoridades e das forças de segurança acerca da ocupação do Complexo do Alemão e da Vila Cruzeiro, o Extra dá voz a moradores, criminosos e suspeitos. Tais atores também aparecem ilustrados ao longo da reportagem e ganham espaço nas interlocuções, tanto nos diálogos expressos pelos balões de fala, quanto nos depoimentos marcados entre aspas nos recordatórios. Porém, diferentemente, suas identidades permanecem anônimas. Quanto ao traço utilizado nas ilustrações desses atores, predomina um estilo mais cartunesco, em oposição a um estilo mais realista empregado na construção visual das autoridades e das forças de segurança. Esse contraste é perceptivel, por exemplo, na página a seguir (Figura 8), cujos três quadros superiores narram a rendição de um criminoso e os cinco quadros abaixo, a troca das bandeiras da Polícia Civil e do Estado do Rio de Janeiro. 
Figura 8 - Estilo cartunesco versus estilo realista em $O$ fim

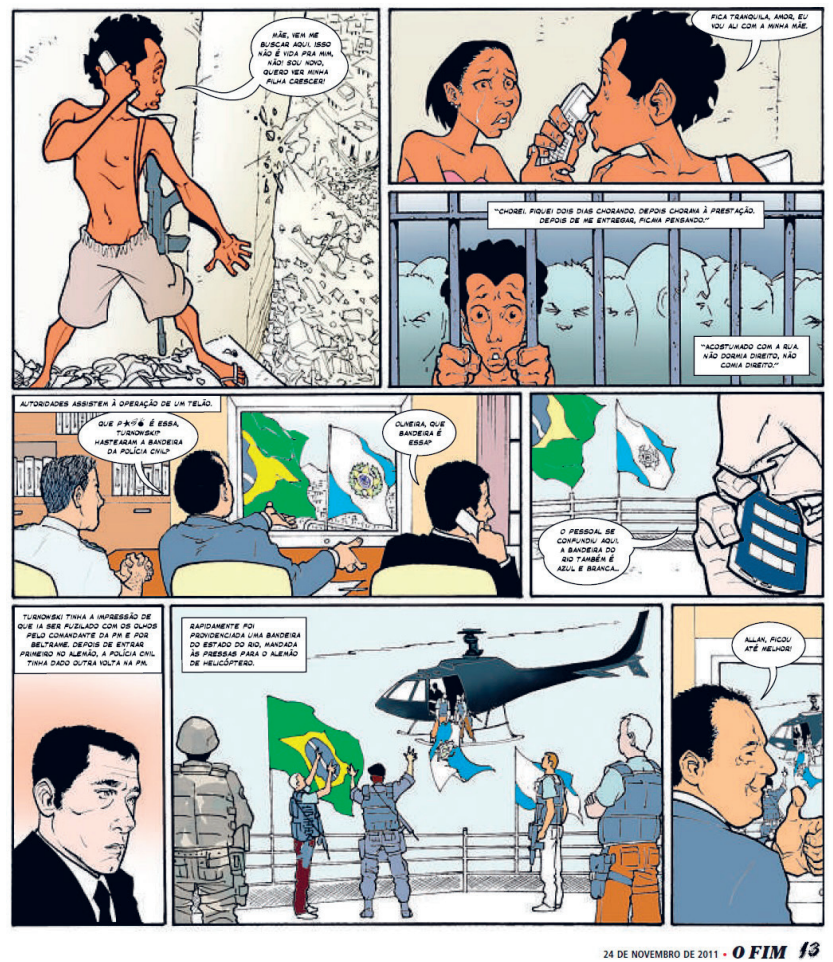

Fonte: O fim (2011, p. 13).

Antes de encerrarmos a análise, cabem considerações adicionais sobre a exploração feita pelo Extra de recursos da linguagem quadrinística. Identificamos um uso extensivo da narração, circunscrita no interior dos recordatórios. A transformação da narração em diálogos breves é o que geralmente dinamiza a parte verbal das histórias em quadrinhos. Mas, nesse caso, o enunciador do jornal prescinde de uma farta distribuição de falas em balões em favor da manutenção de um narrador preponderante. Pela exacerbação da narração, o ritmo de leitura é desacelerado. Mas o efeito de fidelidade inerente à linguagem jornalística é construído. Quanto ao uso dos balões de fala, a maioria tem formato normal. Não aparecem, por exemplo, balões splash (com linhas pontiagudas), de pensamento (ondulados) ou tremidos - que costumam representar medo (SANTOS, 2015, p. 29). Prevalecem também quadros largos e requadros retangulares. Como explica Eisner (2010, p. 92), "um quadrinho estreito evoca uma sensação de encurralamento, de confinamento, ao passo que um quadrinho largo sugere abundância de espaço para movimento - ou fuga" e "o requadro convencional, tipo contêiner, mantém o leitor distanciado - ou fora do quadrinho, por assim dizer" (EISNER, 2010, p. 48).

Finalizamos destacando alguns elementos relevantes das últimas páginas de O fim. O enunciador dá continuidade à atribuição de um valor eufórico à operação, o que fica expresso em trechos da narração como "o tráfico deixou histórias de terror para quem vive no Complexo do Alemão e na Vila Cruzeiro" (O FIM, 
2011, p. 15), que introduz o seguinte depoimento: “já tiveram épocas muito ruins aqui. Os caras roubavam, matavam morador, penduravam cabeça de gente que eles matavam no poste" (O FIM, 2011, p. 15, grifo nosso). O conteúdo verbal grifado é representado visualmente (Figura 9). Mas, como explicita o narrador, "nem todas as notícias são boas". A matéria se encerra mencionando a convivência dificil entre moradores e militares nas comunidades "pacificadas" e as condições precárias ainda enfrentadas por quem vive nessas regiões.

Figura 9 - Quadro da direita retrata cabeças penduradas em poste em O fim

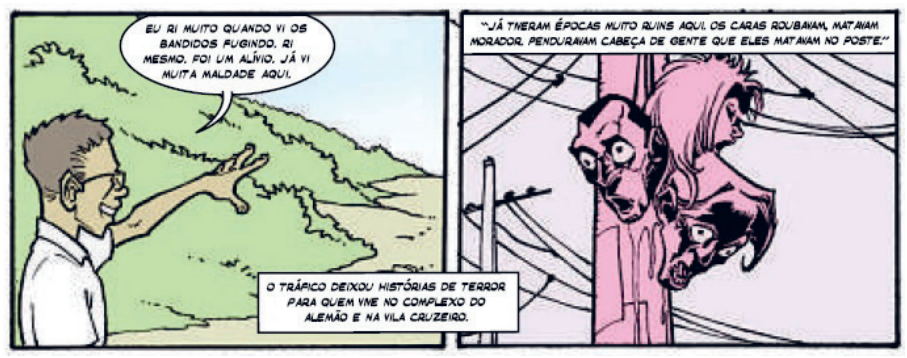

Fonte: O fim (2011, p. 15).

\section{CONSIDERAÇÕES FINAIS}

Em O fim, identificamos um grande esforço por parte do enunciador do Extra para a construção do efeito de sentido de realidade inerente ao jornalismo, a partir da adoção de estratégias como: construções visuais icônicas; um estilo de desenho mais referencial; reprodução de frames; ancoragem, dada pela explicitação de dados precisos; apresentação de diversas versões do episódio narrado, com a delegação de voz a autoridades, forças de segurança, moradores, criminosos e suspeitos; e narração preponderante. As unidades básicas das HQs também estão presentes: ilustrações, quadros, requadros, calhas, balões, rabichos, recordatórios, onomatopeias e linhas cinéticas. Entretanto, predominam o conteúdo verbal, quadros largos, requadros retangulares e balões de fala normais, entre outros elementos que acessam a arena perceptiva dos leitores pelo conforto. Não há momentos de grande impacto, apelos sensiveis construídos, por exemplo, pelo uso de hipérboles, de um alto índice de sobreposições visuais e verbais ou por muitas demandas de catálise, como muitas HQs fazem.

Assim, se por um lado, a opção por uma exploração maior dos recursos da linguagem jornalística permitiu ao Extra fazer a manutenção do caráter factual da ocupação do Complexo do Alemão, por outro, imprimiu na reportagem um ritmo de leitura mais lento do que o previsto para os quadrinhos. Com isso, mostramos como as coerções de linguagem influenciam fortemente no resultado de uma adaptação. Comprovamos, ainda, a nossa hipótese inicial de que o JQ busca construir um simulacro de aproximação ao discurso jornalístico tradicional. Entretanto, vale ressaltarmos como a imersão do jornalismo no universo dos quadrinhos pode proporcionar uma abertura à explicitação da subjetividade. $\mathrm{Na}$ análise de $O$ fim, vimos como o enunciador do Extra se posiciona claramente em alguns momentos, por exemplo, euforizando a operação e expondo "deslizes" ocorridos durante a sua execução. 


\section{The Complexo do Alemão favelas occupation in the comics report of Extra}

Abstract: In the midst of a profusion of artistic and cultural works adaptations to different media and a vigorous discussion about the press future, comics journalism gains prominence as an alternative to supply the current market demands. This article aims to discuss this incipient semiotic object, through the analysis of the comics report $O$ fim, by the Brazilian newspaper Extra, about the occupation of the Complexo do Alemão favelas by the security forces of Rio de Janeiro State. Based on discursive semiotics, we examine how journalistic language is reconstructed in comics language in this case and the tension between reality and fictionality meaning effects that results from this movement.

Keywords: Comics journalism. Discursive semiotics. Hybrid languages.

\section{REFERÊNCIAS}

ASSOCIAÇÃO NACIONAL DE JORNAIS - ANJ. Os maiores jornais do Brasil de circulação paga, por ano. 2011.

BARROS, D. L. P. Teoria semiótica do texto. São Paulo: Ática, 2005.

CAMPOS, H. Da tradução como criação e como crítica. In: CAMPOS, H. Metalinguagem. São Paulo: Cultrix, 1976. p. 21-38.

EISNER, W. Quadrinhos e arte sequencial. São Paulo: WMF Martins Fontes, 2010.

FIORIN, J. L. Semiótica e comunicação. Galáxia - Revista Transdisciplinar de Comunicação, Semiótica, Cultura, São Paulo, n. 8, p. 13-30, 2004.

FIORIN, J. L. As astúcias da enunciação. São Paulo: Ática, 2005.

FIORIN, J. L. Elementos de análise do discurso. São Paulo: Contexto, 2011.

FLOCH, J-M. Petites mythologies de l'oeil et de l'esprit: pour une sémiotique plastique. Amsterdam: Hadès-Benjamins, 1985.

FONTANILLE, J. Formes de vie. Liège: Presses universitaires de Liège, 2015.

GOMES, C. M. M. A Cartomante: traduções intersemióticas do conto de Machado de Assis. 2015. Dissertação (Mestrado em Estudos de Linguagem)-Universidade Federal Fluminense, Niterói, 2015.

GOMES, R. S. Relações entre linguagens no jornal: fotografia e narrativa verbal. Niterói: EdUFF, 2008.

HUTCHEON, L. Beginning to theorize adaptation: What? Who? Why? How? Where? When? In: HUTCHEON, L. A theory of adaptation. Abingdon: Routledge, 2013. p. 1-32.

JAKOBSON, R. Aspectos linguísticos da tradução. In: JAKOBSON, R. Linguística e comunicação. São Paulo: Cultrix, 1969. p. 63-72.

LOTMAN, I. La semiosfera I: semiótica de la cultura y del texto. Madri: Cátedra, 1996.

MANCINI, R. O hibridismo entre linguagens na perspectiva tensiva: uma análise de Sin City. In: SEMINÁRIO DO GEL, 56., 2008, São José do Rio Preto. Anais... São José do Rio Preto: GEL, 2008. 
MANCINI, R. Sem Greimas, com Greimas, após Greimas, cem Greimas. Estudos Semióticos, São Paulo, v. 14, n. 1, p. 22-27, 2018. Disponivel em: http://www. revistas.usp.br/esse/article/view/144306/138705. Acesso em: 8 abr. 2019.

MANCINI, R.; ALT, J. Quadrinhos: do papel à internet. In: TEIXEIRA, L.; CARMO JÚNIOR, J. R. (org.). Linguagens na cibercultura. São Paulo: Estação das Letras e Cores, 2013. p. 91-109.

MANCINI, R.; TROTTA, M.; SOUZA, S. M. Análise semiótica da propaganda Hitler, da Folha de São Paulo. In: COLÓQUIO CPS - Atelier estratégias enunciativas em textos sincréticos, 13., 2007, São Paulo. Anais... São Paulo: PUC-SP, 2007.

MORETZSOHN, S. "Profissionalismo" e "objetividade": o jornalismo na contramão da política. In: Biblioteca On-line de Ciências da Comunicação. Covilhã: UBI, 2001. Disponivel em: http://www.bocc.ubi.pt/pag/moretzsohn-sylvia-profissionalismo-jornalismo.pdf. Acesso em: 8 abr. 2019.

NECO, J. Imagem, narrativa e discurso da reportagem em quadrinhos de Joe Sacco. 2010. Dissertação (Mestrado em Jornalismo)-Universidade Federal de Santa Catarina, Florianópolis, 2010. Disponivel em: https://repositorio.ufsc.br/ bitstream / handle / 123456789/94406/283581.pdf? sequence=1\&isAllowed=y. Acesso em: 8 abr. 2019.

O FIM - O dia em que a bandidagem do Rio perdeu a fama de valente. Jornal Extra, Rio de Janeiro, 24 nov. 2011.

PLAZA, J. Tradução intersemiótica. São Paulo: Perspectiva, 2003.

SANTOS, R. E. Aspectos da linguagem, da narrativa e das histórias em quadrinhos: convenções e rupturas. In: VERGUEIRO, W.; SANTOS, R. E. (org.). A linguagem dos quadrinhos: estudos de estética, linguística e semiótica. São Paulo: Criativo, 2015. p. 22-47.

ZILBERBERG, C. Síntese da gramática tensiva. Significação - Revista Brasileira de Semiótica, São Paulo, n. 25, p. 163-204, 2006.

ZILBERBERG, C. Elementos de semiótica tensiva. São Paulo: Ateliê Editorial, 2011.

Recebido em 14 de novembro de 2018. Aprovado em 23 de março de 2019. 